\title{
Co-simulation of energy transition in residential sectors of Chinese lower-tier cities
}

\author{
Daniel van Bilsen ${ }^{1, *}$, Yilin Huang ${ }^{1}$ and Li Fen ${ }^{2}$
}

${ }^{1}$ Delft University of Technology, Faculty of Technology, Policy and Management, Jaffalaan 5, Delft, 2628 BX, The Netherlands

${ }^{2}$ Shenzhen Institute of Building Research, 1F, Building 7, Zhongguancun National Defense Science and Technology Park, Haidian District, Beijing 100081, China

*Corresponding author. Email address: D.vanBilsen@tudelft.nl

\begin{abstract}
China is undergoing large changes to tackle carbon dioxide emissions and air pollution. While the top-down governance allows for clear setting of emission reduction targets for industrial sectors and major cities, reducing emissions in residential sectors in smaller (the so-called low-tier) cities remain challenging and often unaddressed. This paper studies policy options to reduce emissions in residential sectors in low-tier Chinese cities. We conducted interviews and surveys in the city of Jingmen in the Hubei province and developed simulation models with feasible policy options and realistic consumption choice preferences. The simulation provided insights to the policies on reducing household coal consumption and ensuing emissions. Our research found that top-down restrictive policies such as coal ban and coal tax are effective in reducing emissions. They, however, restrict access to affordable energy for heating and cooking, especially within rural areas. They hence need to be combined with supportive policies such as electricity subsidy to yield long-term positive impact.
\end{abstract}

Keywords: modelling, simulation, residential energy consumption, household emissions

\section{Introduction}

Over the last decade, the Chinese government invested significant resources and implemented ambitious policies in curbing emissions and pollution (Jia, 2018; Dong, Sun, Li \& Jiang, 2017). The country is a front runner in emission reduction and investment in renewables (Yang, Hu, Tan, \& Li, 2016; Sahu, 2018; Wang et al., 2019). Although its coal consumption is reduced in proportion to the its total energy consumption (from $70 \%$ in 2011 to $59 \%$ in 2018), China's total coal consumption is still high: 4.64 billion tons used in 2018 (Zhao \& Alexandro, 2019; Climate Action Tracker, 2019). Around $81 \%$ of China's emissions comes from coal. (EIA, 2020). Many households in China, particularly in small cities and rural areas known as low-tier prefectures, are using biomass and more often coal as direct energy sources for heating and cooking. These solid fuels are inexpensive, but they cause severe air pollution (indoors and outdoors) and are damaging to public health. Besides sulphur dioxide emissions that lead to acid rain and soil acidification (T. J. Wang, Jin, Li, \& Lam, 2000), direct burning and incomplete combustion of those fuels in combination with poor household ventilation incurred household air pollution that is estimated to cause each year 420,000 premature mortalities in China (Delang, 2016).

The current environmental investments and policies in China often focus on major sectors such as industry, agriculture and power generation (Gu et al., 2018), as well as on major administrative regions (including the so-called high-tier cities) such as

(C) 2020 The Authors. This article is an open access article distributed under the terms and conditions of the Creative Commons Attribution (CC BY-NC-ND) license (https://creativecommons.org/licenses/by-nc-nd/4.0/). 
Beijing, and Guangzhou ( $\mathrm{Hu} \& \mathrm{Mu}, 2019$; Su, Chen, \& Yang, 2016; Ou et al., 2017). For national policies, such as phasing out coal-fired power plants and national emission trade scheme (Sandalow, 2018), China's hierarchical governance structure has the advantage of effective top-down goal setting and decisionmaking. The implementation however is left to the local officials who need to establish local policies and regulations (Gilley, 2012; Qi, Ma, Zhang, \& Li, 2008; National Development and Reform Commission 2008). The local policy design and implementation requires (bottom-up) data collection to accommodate local needs, for which the Chinese top-down information flows experience limitations. There is limited research on how policy design and implementation at local level can motivate residents to move away from traditional solid fuels such as coal and biomass (Jiang \& O'Neill, 2004; Muller \& Yan, 2014).

This paper investigates policy options to stimulate household energy transition in low-tier prefectures in China. An important goal is to stimulate such transition without forcing consumption reduction for heating and cooking (currently often using traditional solid fuels), and to provide affordable alternatives. We conducted a case study on the city of Jingmen, which shares many characteristics with other Chinese prefectural cities. We conducted interviews and surveys, and developed simulation models to study the policy implications on consumption and emissions. In Section 2, we describe the interview and survey results of Jingmen. These results were used to develop the models which are presented in Section 3. Section 4 discusses the experimental results and policy implications.

\section{Interviews and Surveys in Jingmen}

Jingmen is a low-tier prefecture in Hubei province. It has a population of just over three million. Our study in Jingmen consists of the use of local data, conducted interviews and surveys with local government officials and residents.

The interviews were carried out with three different target groups: (1) interviews with the municipal government (around thirty minutes to one hour each), e.g. the Development and Reform Commission, and the Housing Construction Committee, to explore what policies the government can legally implement in coherence with the party agenda. These interviews were conducted in order to better understand the problem from the perspective of the local government, which policies were currently considered, and to which extent the current policies are already in their implementation phase. (2) Interviews with technical expert groups, e.g. the Ecological Environment Bureau (around 30 minutes), and members of the High-Tech Industry Campus (around 3 hours), to understand what policies are feasible from a technical point; (3) Around 10 interviews were conducted with individual residents to inquire about the potential reaction to policies from a social viewpoint. The length of these interviews varied between 5-20 minutes, depending on the cooperation of individual residents as they were carried out individuals who were willing to further discuss their preferences regarding their energy consumption after conducting the survey in person. Surveys $(n=616)$ were conducted to gain knowledge about demographics, current household fuel consumption, and to gain insight about the reason why the residents consume certain fuel types.

\subsection{Interview Results: Policy Design}

The Jingmen government considers five core policies for implementation. The goal is to induce a shift in residential energy demand from traditional energy sources (coal and biomass) to cleaner sources such as electricity and gas. We modelled these policies and their combinations in the simulation model. The five policies are: (1) A complete ban on residential coal use; (2) An (incremental) price tax on residential coal by $0.02 \mathrm{CNY} / \mathrm{MJ}$ per year; (3) A fixed electricity subsidy of $25 \%$; (4) An increased accessibility to (natural) gas through a $20 \%$ faster rate of natural gas pipeline construction throughout the city; (5) Increase residential awareness by providing information and education about health and environmental impact about the consumption of coal and biomass versus gas and electricity. These policies can be divided into two groups: policies (1) and (2) are restrictive policies as they prohibit or limit access to undesirable fuel types; policies (3) to (5) are supportive policies as they ease the access to desirable fuels.

The other policies such as demand-based (dynamic) electricity pricing, and supply-side policies such as transition towards renewables fall outside the scope of our study. Due to the centralised provision by the Central China Power Grid, the sources (e.g. renewables) of electricity falls under the jurisdiction of the central supplier, not that of the local governments. The local renewable generation by households in low-tier prefectures is also not feasible given the context. In our study, we assume that the electricity consumption itself does not create emissions, which is already accounted at the generation phase.

\subsection{Survey Results: Consumption Behaviours}

The survey got respondents from rural and urban areas. This distribution is important as energy consumptions in rural and urban areas showed distinct patterns. We inquired information about the respondents' demographics, current household fuel consumption and choice preferences.

\subsubsection{Demographics and Background of Respondents}

There is a growing inequality in income between urban and rural areas in China (Molero-Simarro, 2017). This is also reflected in the survey response data: around half of the respondents in the rural area had an annual income of less than 30,000 CNY (around €3,880); 
almost half of the urban respondents reported to have an annual income of over 80,000 CNY (around $€ 10,340)$. The rural population is on average older and has a lower level of education, in comparison to the urban population.

\subsubsection{Current Household Energy Consumption}

The level of energy consumption increases with the level of income. This increase diminishes at a yearly income of around 100,000 CNY per year. In general, the respondents spend $2-7 \%$ of their income on energy. Aside from energy consumption for heating and cooking, there is non-substitutable consumption (where electricity cannot be replaced by fuels) for appliances such as televisions or lighting. The survey acquired the information about the use of these appliances. The urban population possesses a lot more appliances compared to the rural population.

\subsubsection{Choose Preferences of Energy Source}

The urban and rural areas showed different attitudes to fuel consumption. Residents in both areas are aware of the potential dangers of coal, yet unaware of the harm of biomass consumption to health. The rural respondents consumed more harmful fuels such as coal out of necessity as there is a lack of cleaner alternatives. They often are unaware of, or not in a position to have health and environment concerns in the first place. Many respondents in urban areas already consume cleaner energy such as gas and electricity as these are already accessible and relative cheap to use. They believe that pollution is a public issue and they are concerned about the environmental and health issues.

\section{Model overview}

The overall model can be briefly described with six key aspects. First, the geographical scope of the model is the urban and rural areas of Jingmen. As the rural area has distinct energy consumption characteristics compared to the urban area, they are modelled with different parametric settings. Second, the modelling focuses on the residential sector, in particular the energy consumption for household cooking and heating, where the energy transition policy shall take effect. Third, four forms of energy (sources) are considered: electricity, (natural and petroleum) gas, biomass (e.g., firewood, crop, straw and residue) and coal. They are listed in order from the most to least desirable from the perspective of policy makers in Jingmen. Fourth, the model forecasts (and backcasts) energy consumption from 2015 until 2030, which covers China's three consecutive Five-Year Plans (FYPs). As the energy consumption data from 2015 to 2020 was not yet available at the time of research, the energy and census data from 2010 to 2015 (Hubei Provincial Bureau of Statistics 2020) are used to configure the model parameters. Fifth, the policy options identified in Section 2.1 are implemented as of
2020 in the simulation experiments (see Section 3.2.6). Sixth, from the simulated energy consumption, the model estimates the carbon dioxide $\left(\mathrm{CO}_{2}\right)$ and respirable particulate matter $\left(\mathrm{PM}_{10}\right)$ emissions.

\subsection{Co-simulation of Vensim and LEAP models}

Two models are used to simulate the energy demand and subsequent emissions, one developed in Vensim and one developed in LEAP. The Vensim model simulates the energy policies and household energy consumptions for cooking and heating, while the LEAP model aggregates the energy consumption and estimates the resulting $\mathrm{CO}_{2}$ and $\mathrm{PM}_{10}$ emissions. Prior to the simulation run, a user can configure the policy options and their conditions, e.g. to implement a policy in a given year. The two models communicate through co-simulation as illustrated in Figure 1.

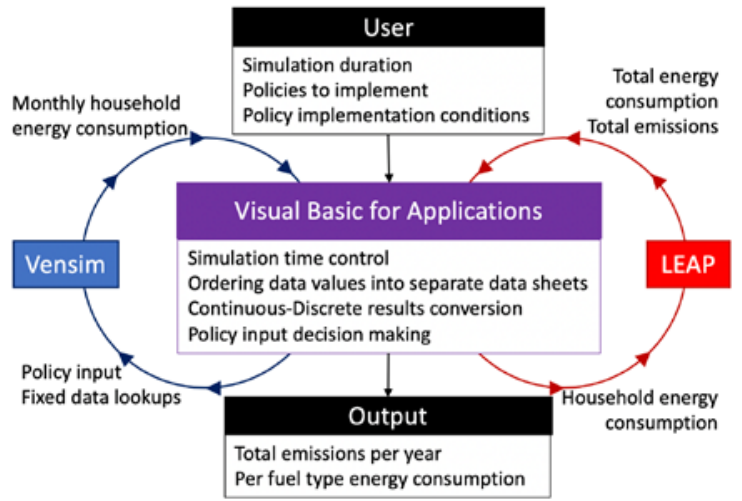

Figure 1. Information flow of the so-simulation

The simulation time-step of Vensim model is one month and the LEAP model one year. They are synchronized each year (enabled by Visual Basic). Vensim's monthly consumption output is aggregated and converted to yearly sums, read by LEAP. The LEAP model uses this household energy consumption and estimates the yearly emissions. The emission values are then transferred back to the Vensim model which triggers the policies, if applicable, for the following year. This interaction iterates until 2030.

\subsection{Vensim System Dynamics Model}

The Vensim model has five sub-models, each of which is configured for the rural and urban areas separately. The first three sub-models correspond to the three utility factors: (1) the energy price, (2) the convenience of using each form of energy, (3) the knowledge (of a household) about energy consumption (regarding the four forms of energy), e.g., their impact to health and environment; and the willingness of consumption behaviour change, e.g. to consume cleaner energy if applicable. Sub-models 4 and 5 compute the total utility and the average amount of household consumption for each energy source.

In literature, Multinomial Logit Models (MLMs) are often used for fuel choices (Alem et al., 2016; Hosier \& Dowd, 2002; Liao et al., 2019). They model the utility 
of each choice by calculating the logarithmic fraction of the utility sum of all options. The utility of each type of fuel in this study is a function of the price, convenience, and residents' knowledge of consumption and willingness to change. Figure 2 provides the main model variables and the interactions between each of the sub-models. Each of the three sub-models calculate a 'utility'-related value of a fuel for each month. Each fuel type is expressed using a corresponding price-utility, convenience-utility and knowledge and willingnessutility, all ranging between $[0,1]$. These values are then combined to attain a value that represents the total utility of the fuel, the sum of the utilities of fuel is equal to 1. In this way, the final utility of each individual fuel represents the percentage of people using this certain energy source for cooking and heating purposes. This is calculated in sub- model (4). Additionally, the results from sub-models 1-3 will influence the total energy demanded per household (e.g. a lower price of electricity will cause more people to use electricity, and more electricity to be used per individual). Sub-model 5 therefore combines results from sub-models $1-4$ to attain a total energy consumption per energy type. These results are subsequently sent to LEAP, which calculates the total emissions as a result of the consumed energy. The following paragraphs will lay out each of the submodels in further detail.

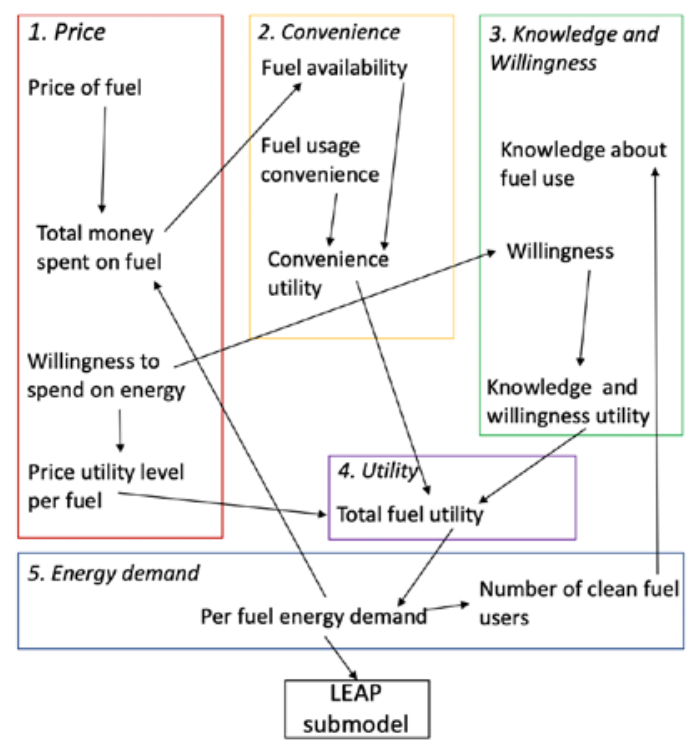

Figure 2. An overview of the system dynamics model for energy policy and residential energy consumption

\subsubsection{Sub-model 1: Energy Price}

The fuel price sub-model focuses on the prices of fuel and the proportion income spent on fuel consumption. Jiang \& O'Neill (2004) and Wang et al. (2015) reported that people generally pay $3-10 \%$ of their monthly income on energy. Our survey showed that the respondents spent between $2-7 \%$, which is consistent with literature. The price of each fuel in the Vensim model is constant if there is no policy intervention.
The prices are based on the CEIC database (CEIC, 2019) and are converted to $\mathrm{CNY} / \mathrm{MJ}$ : biomass 0.000 , coal 0.020 , gas 0.037 , and electricity 0.147 .

The survey shows that that price plays a significant role in the choice of fuel type and quantity consumed in the rural area. In accordance with the energy ladder hypothesis presented by Hosier \& Dowd (2002), people are more likely to move over to more sophisticated types (i.e. cleaner, more convenient, and often more expensive) of fuel when income rises. Liao et al. (2019) confirmed the existence such a fuel ladder in China. In the experiments without policy intervention, the market price is the price people need to pay for their fuel. The fraction of income ( Fr) spent on a fuel type is calculated by equation (1):

$$
F r_{\text {income }}=\frac{D_{\text {fuel }} * P_{\text {fuel }}}{\text { Income per capita }}
$$

Where $D$ is the average consumption for a certain type of fuel, calculated as output from the previous timestep. $P$ is the fuel price (in $\mathrm{CNY} / \mathrm{MJ}$ ). The subsequent price-related utility value is calculated using equation (2). The utility of fuel price is not (inversely) linear to the percentage of income paid. We assume that the more people pay for their fuel, the less likely people are to choose a more expensive fuel.

$$
p_{\text {utility }_{\text {fuel }}}=\min \left(1, \max \left(0, \ln \left(\frac{F r_{\text {income, } m a x}}{F r_{\text {income }}}\right)\right)\right)
$$

where $p_{\text {utility }}$ represents the price-related utility value of the fuel. This sub-model assumes that biomass is free (i.e. people collect the firewood themselves) so that biomass has a maximum price utility of 1 .

\subsubsection{Sub-model 2: Convenience of Energy Consumption}

As people prefer to use a certain type of fuel for convenience, the utility of a fuel source increases when the source is more accessible. Electricity is the most convenient and has a 'convenience' - utility value of 1 . Gas is assumed to be $30 \%$ less convenient if it comes from propane tanks rather than pipelines. Thus, its convenience defined as following:

$$
c_{\text {utility }} \text { gas }=\% \text { connected }+0.7(1-\% \text { connected })
$$

Where \%connected refers to the percentage of households that are connected to the natural gas grid. Biomass is more convenient (and more available) to use in the rural area than in the urban area. Due to the residue it leaves behind, biomass is assumed to be less convenient than propane gas and is standardly set at 0.4 . The convenience of coal depends on how easy it is to acquire, e.g., how many retailer stores. The number of stores is based on the profits of sellers which 
further depend on the demand.

\subsubsection{Sub-model 3: Knowledge and Willingness}

People's knowledge deficit about the environmental impact of fuel consumption poses significant constrains for them to engage in environmental behaviors such as shifting to cleaner fuel and more efficient consumption (Huang \& Warnier, 2019). Those who are more aware of the environmental impact often have more positive attitudes toward behavioral change (Latif, Omar, Bidin, \& Awang, 2013; Paço \& Lavrador, 2017). But they also need to make conscious decisions for specific actions that lead to behavioral change (Huang \& Warnier, 2019). In our study, this behavior change refers to the use of another fuel source which can be sometimes more expensive or less convenient, such as using gas rather than coal because of the health dangers it may pose.

This sub-model uses learning-by-searching and learning-by-doing mechanisms adapted from Bildik, Daalen, Yü, Ortt, \& Thissen (2015) and Struben \& Sterman (2008). A variable $(K W)$ represents the knowledge and willingness to adopt a new cleaner fuel source in a neighbourhood:

$$
K W_{u_{\text {tilit }}} \text { fuel }_{\text {f }}=K * W
$$

The level of knowledge $(K)$ is determined by knowledge gain $\left(k_{\text {in }}\right)$ and knowledge decay $\left(k_{\text {out }}\right)$.

$$
\frac{d K}{d t}=k_{\text {in }}-k_{\text {out }}
$$

There are two main ways knowledge can be gained: either through learning from other people in the neighbourhood $\left(E_{s o c}\right)$, or through the provision of information $\left(E_{\text {info }}\right)$.

$$
k_{\text {in }}=\left(1-K_{t-1}\right)\left(E_{\text {soc }, t}+E_{\text {info }, t}\right)
$$

The value of $E_{\text {soc }}$ variables depend on the amount of people using clean energy, defined in equation (6). The main drivers of this model are the loop in which 'clean energy' becomes the 'talk of the town', i.e. people are becoming aware of the importance because other people are using clean energy types. The perceived importance of clean energy depends on the amount of people are currently using the clean energy. It concerns the 'social cohesion' amongst members in the urban and rural areas.

$$
E_{\text {soc }}=c_{\text {soc }} * K_{t-1} * F r_{\text {clean }, t-1}
$$

The value $c_{s o c}$ is a coefficient that refers to the social cohesion within the urban and rural area. These values are estimated as a result of survey questions regarding the knowledge people had regarding the energy consumption of their neighbours, as well as whether the neighbourhood had an impact for citizens in choosing their own fuel. The variable $\mathrm{Fr}_{\text {clean, },-1}$ refers to the fraction of people in the region that are already consuming clean fuel (either electricity or gas) in the previous month.

The amount of knowledge gained from information outlets depends on the amount of information that is put out to the people regarding clean energy consumption. This measure is activated and adjusted as a policy option in the form of a variable $c_{\text {info }}$ (Policy 5). It is further dependent on the amount of information that is retained by an individual. The information is delayed as it takes time for the policy to be implemented, take effect and also for the people to adjust their behaviour accordingly. The value Einfo is therefore calculated as following:

$$
E_{\text {info }}=c_{\text {info }}\left(1-K_{t-1}\right)
$$

Any loss of knowledge is due to a lack of overall exposure and general decay as people's interests are shifting away over time. If there are not enough people who have adopted the clean energy, and the 'knowledge and willingness' of people to adopt the technology will reduce as a result of lack of knowledge and interest. The decay of knowledge $\left(k_{\text {out }}\right)$ is calculated using the same formula used by Bildik, Daalen, Yü, Ortt, \& Thissen (2015), in which the amount of knowledge naturally decays (i.e. due to a loss of interest) as an exponent depending on the amount of knowledge the people have.

$$
k_{\text {out }}=\Theta_{0} \frac{\exp \left(-4 \varepsilon\left(K_{t-1}-\tau_{\text {ex }}\right)\right.}{1+\exp \left(-4 \varepsilon\left(K_{t-1}-\tau_{e x}\right)\right.}
$$

$\Theta_{o}$ stands for the maximum rate of knowledge decay. This value is slightly higher in the urban area compared to the rural area as the 'lifestyle speed' and change in the urban area is generally faster than in the rural area. Variable $\varepsilon$ is the rate of knowledge decay at $t$, which is inversely proportional to the exposure rate, $\tau_{\text {ex }}$.

When people are knowledgeable about clean and efficient energy, they also need to be willing to use the energy, as this often means that they need to spend more to make the transition. Our survey shows that people are more willing to use or change to a fuel source which is affordable, in particular when a small portion of income is spent on energy. This willingness to adopt therefore depends on the amount of money people currently already spend on energy as a portion of their maximum willingness to spend. This maximum amount is set at $5 \%$ (Frincome,max $)$. This leads to the following formula for the willingness:

$$
W=c_{s W}\left(\max \left(0, \frac{F r_{\text {income } \max }-F r_{\text {income }, t-1}}{F r_{\text {income } \max }}\right)\right)
$$


Where $c_{s w}$ is the coefficient of willingness taken as the proportion of surveyed individuals who stated they would be willing to pay more if this could give them cleaner energy.

\subsubsection{Sub-model 4: Energy utility}

Literature investigating population fuel choice often investigates fuel preferences using Multinomial Logit Models (Alem et al., 2016; Hosier \& Dowd, 2002; Liao et al., 2019). This type of choice modelling considers the utility of each available choice by calculating its logarithmic fraction to of the sum of utility of all choices possible. The relative utility of each individual fuel is the proportion of the total population that is using a certain type of fuel. The utility of each available fuel is a function of the mechanisms of price, convenience, knowledge and willingness described earlier. In order to obtain the utility of each fuel type, the sub-model KPI's are multiplied by a coefficient (c) representing their relative importance in determining the type of fuel. A calibrated fixed error term $(\xi)$ is added to each of the utilities to compensate for other assumptions made such as the limited choice of which fuel types available. The values of $\xi$ are calibrated between -3 and 3 , using consumption data available between 2010-2015. This provides the following function for each fuel type (e - electricity, $g$ - natural gas, cl - coal, b - biomass):

$$
\begin{gathered}
\ln \left(u_{e, t, r}\right)=\frac{c_{P} P_{e}+c_{C} C_{e}+c_{K W} K W_{e}}{c_{P}+c_{C}+c_{K W}}+\xi_{e} \\
\ln \left(u_{g, t, r}\right)=\frac{c_{P} P_{g}+c_{C} C_{g}+c_{K W} K W_{g}}{c_{P}+c_{C}+c_{K W}}+\xi_{g} \\
\ln \left(u_{c l, t, r}\right)=\frac{c_{P} P_{c l}+c_{C} C_{c l}+c_{K W}\left(1-K W_{c l}\right)}{c_{P}+c_{C}+c_{K W}}+\xi_{c l} \\
\ln \left(u_{b, t, r}\right)=\frac{c_{P} P_{b}+c_{C} C_{b}+c_{K W}\left(1-\beta K W_{b}\right)}{c_{P}+c_{C}+c_{K W}}+\xi_{b}
\end{gathered}
$$

The formulas for the dirty fuels are different from the fuels considered clean, as knowledge and willingness hereby have a negative effect on the total utility. Biomass is considered less harmful than coal, so a factor considering the harmfulness of biomass in comparison to coal $(\beta)$ is multiplied by the knowledge and willingness factors. Subsequently, the relative utility of each fuel type is calculated using the formula:

$$
U_{f}=\frac{u_{f}}{\sum_{i=0}^{4} u_{f_{i}}}
$$

It represents the ratio of households that consume energy $\varepsilon$ for cooking and heating.

\subsubsection{Sub-model 5: Energy consumption}

The actual demand for energy variable represents the expected average amount of energy a family will be using for cooking and heating purposes in the upcoming year. If fuel becomes cheaper and more convenient to use, it will be consumed by a relatively larger portion of the city. However, the total consumption per capita will likely increase too. The actual energy demand therefore increases as a result of the convenience and price total utility variables of all fuels combined, which is denoted as $\chi_{C P}$. On the other hand, the energy demand may also change depending on the knowledge and willingness variables. This determines how people are willing to use less fuel because they are more aware of how to use less and willing to use less because they are implored to do so out of reasons for the environment or health $\left(x_{K W}\right)$.

Using the results from the utility sub-model (4), the $\mathrm{CP}$ and $\mathrm{KW}$-factors are calculated, which are used to calculate the per-household change in energy consumption. The values for $\chi_{K W}$ and $\chi_{C P}$ are calculated using equations 16 and 17 below:

$$
\begin{gathered}
x_{C P, t}=\frac{\sum_{i=0}^{4} c_{C} C_{f_{i}, t-1}+c_{P} P_{f_{i, t-1}}}{4} \\
x_{K W, t}=c_{K W} K W_{t-1}
\end{gathered}
$$

For each factor there is a delay of one month, as it may take a month before people will adjust their consumption quantity (as a result of the monthly energy bill).

The actual impact of $C P_{\text {in }}$ and the $K W_{\text {out }}$ on energy demand are dependent on the current expected average amount of energy as the flows represent a percental change in demand. Furthermore, aside from their indicated names (Convenience and Price, and Knowledge and Willingness) they depend on a minimum threshold value that needs to be reached in order for any effect to take place. If this threshold value is not reached, the flows will turn out to be negative. For convenience and price, residents will use less energy if the combined factor of convenience and price is less than they are willing to put in (as $C P_{\text {in }}$ will be negative). On the other hand, a decrease in knowledge and willingness about saving energy will lead to an increase of energy consumption (i.e. a negative $\left.K W_{\text {out }}\right)$. The average energy demand is therefore modelled as following:

$$
\begin{gathered}
d_{r, t}=d_{r, t-1}+\frac{d d_{r}}{d t} \\
\frac{d d_{r}}{d t}=C P_{\text {in, }, t, t}-K W_{\text {out }, r, t}
\end{gathered}
$$




$$
\begin{gathered}
C P_{\text {in,t }}=d_{t-1}\left(x_{C P, t}-x_{\min , C P}\right)^{3} \#(20) \\
K W_{\text {out }, t}=d_{t-1}\left(x_{K W, t}-x_{\min , K W}\right)^{3}
\end{gathered}
$$

With $d_{r}$ describing the average expected per household energy demand. The final results from sub-model (4) and sub-model (5) will determine the average residential fuel demand per household, as well as the proportion of residents that use specific types of fuels for cooking and heating purposes. These outputs to the Vensim model are used as inputs for the LEAP model.

\subsubsection{Implementation of the energy policies}

Policies are implemented in the Vensim model where the related variables are altered, e.g. the energy prices are increased with taxes or decreased with subsidies; the number of households connected to the pipelines increases with Policy 4. A summary is listed as follows.

- Coal Ban: Coal is removed from the model as an energy source once this policy is implemented.

- Coal Tax: The price of coal in the Price Sub-model is increased by $0.02 \mathrm{CNY} / \mathrm{MJ}$ per year.

- Electricity Subsidy: The price of electricity in the Price Sub-model is decreased by $25 \%$ at the moment of policy implementation.

- Additional Gas Pipelines: the number of households connected to pipelines \%connected in the Energy Convenience Sub-model increases by $20 \%$ at the moment of policy implementation.

- Increasing Awareness: the value of $c_{\text {info }}$ in the Knowledge and Willingness Sub-model is set to 0.5 instead of 0 . This means that additional knowledge gain is achieved through information campaigns.

\subsection{LEAP model}

LEAP (Long-range Energy Alternatives Planning) is an integrated energy-environment accounting model for policy and climate change assessment. It has four major components: energy demand, energy transformation and conversion, resource assessment and environmental impact estimations. Using the data output from the Vensim model, the LEAP model computes the $\mathrm{CO}_{2}$ and $\mathrm{PM}_{10}$ emissions according to the forms and amounts of energy consumed in the rural and urban areas using its 'Technology and Environmental Database' (LEAP, n.d.).

\section{Experimental results}

Our study has simulation experiments with the five policy interventions individually (see Section 2.1) and with their duo combinations. The results of the experiments are compared to that of the no-policy scenario as the baseline. For the no-policy scenario, the energy consumption and $\mathrm{CO}_{2}$ and $\mathrm{PM}_{10}$ emissions rise steadily from 2015 to 2030. This is expected as expected economic welfare will cause an increase in per household energy consumption, while it will not directly lead to a change in fuel type consumption. Table 1 and Table 2 show the consumption and emissions in urban and rural areas in 2015 and 2030 (without policy intervention) respectively.

Table 1. Consumption (Terajoules) and emissions (Metric Tons) in Jingmen in 2015.

\begin{tabular}{lllll}
\hline 2015 & & Urban & Rural & Total \\
\hline Consumption & Electricity & 2531 & 2144 & 4675 \\
(Terajoules) & Gas & 2542 & 339 & 2881 \\
& Coal & 710 & 657 & 1367 \\
& Biomass & 0 & 181 & 181 \\
& Total & 5783 & 3321 & 9104 \\
\hline Emissions & $\mathrm{CO}_{2}$ & 207633 & 99601 & 307234 \\
(Metric Tons) & $\mathrm{PM}_{10}$ & 65 & 76 & 141 \\
\hline
\end{tabular}

Table 2. Consumption (Terajoules) and emissions (Metric Tons) in Jingmen in 2030.

\begin{tabular}{lllll}
\hline $\mathbf{2 0 3 0}$ & & Urban & Rural & Total \\
\hline Consumption & Electricity & 12030 & 5251 & 17281 \\
(Terajoules) & Gas & 6729 & 3569 & 10298 \\
& Coal & 753 & 2209 & 2962 \\
& Biomass & 0 & 590 & 590 \\
& Total & 19512 & 11619 & 31131 \\
\hline Emissions & $\mathrm{CO}_{2}$ & 445159 & 468318 & 913477 \\
(Metric Tons) & $\mathrm{PM}_{10}$ & 69 & 255 & 324 \\
\hline
\end{tabular}

Simulated values, assuming no policy intervention.

The increases in the no-policy scenario are significant, with an average increase of around $915 \mathrm{TJ}$ and $553 \mathrm{TJ}$ per year in the urban and rural areas respectively. The main reason for this is the expected increase in per-household income in urban (expected to increase from 75,000 CNY in 2015 to $160,000 \mathrm{CNY}$ in 2030) and rural areas (expected to increase from $16,000 \mathrm{CNY}$ in 2015 to $55,000 \mathrm{CNY}$ in 2030), stated by the Jingmen Development and Reform Commission. Additionally, interviews with the High-Tech Industry Campus hinted at significant improvements made in urban infrastructure of energy supply.

The effects of different policy interventions are shown in Figure 4. The $\mathrm{x}$-axes indicate the aggregated amount of energy consumption in proportion to that of the no-policy scenario, which is at point $(1,1)$. The $\mathrm{y}$-axes indicate the total amount of $\mathrm{CO}_{2}$ or $\mathrm{PM}_{10}$ emissions in proportion to that of the no-policy scenario. 


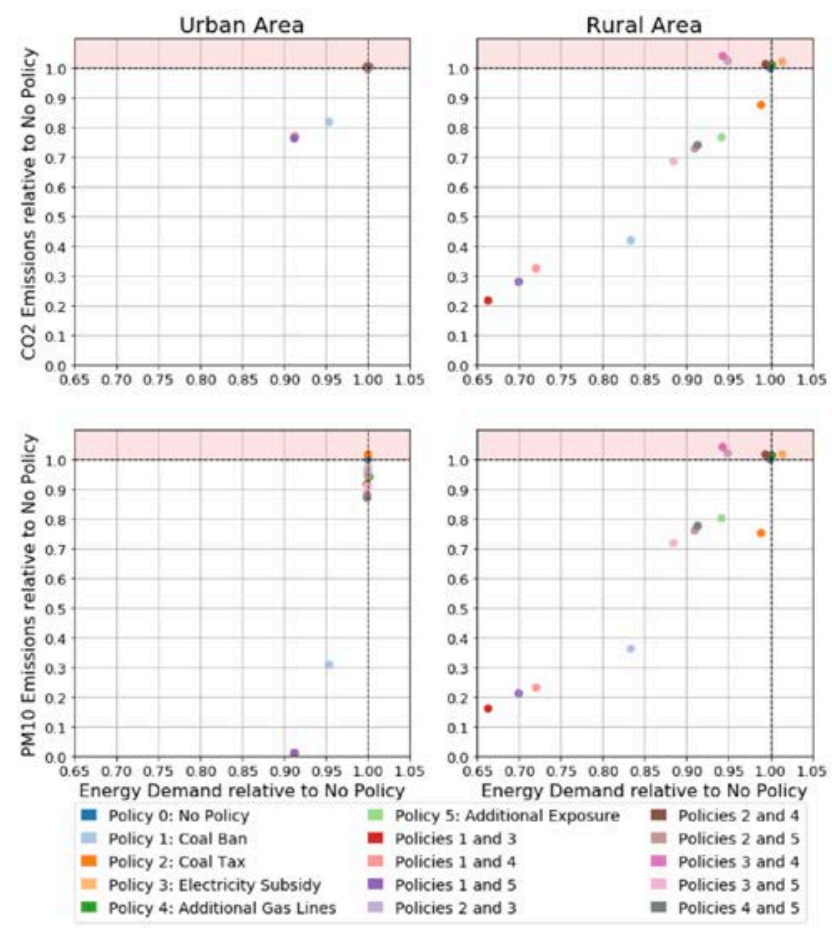

Figure 4. Energy Consumption, $\mathrm{CO}_{2}$ and $\mathrm{PM}_{10}$ Emissions In 2030 with Policy Options. Results relative to the No-Policy Scenario.

The experimental results of the policies are discussed in the following sub-sections. Due to space limits, not all results presented are shown by figures. In practice, urban and rural areas can implement policies separately. However, as each policy is tested in both areas, they will be discussed under a single header.

\subsection{Policy 1: Coal ban}

A ban on coal consumption will be very effective in reducing emissions for both, the rural and urban areas in Jingmen. The coal ban is effective because it takes away a fuel alternative rather than inducing a change in household consumption behaviour. The removal of coal as a fuel alternative will reduce the $\mathrm{CO}_{2}$-emissions to less than half of that expected in 2030 under nopolicy conditions. The $\mathrm{PM}_{10}$-emissions will drop directly from 150 to 50 metric tonnes as a result of the coal ban. Afterwards, no significant rise in $\mathrm{PM}_{10}$ emissions is expected up until 2030. However, this policy will impose the largest energy demand reduction which can be problematic. A coal ban could lead to a demand reduction of up to $30 \%$ in 2030 , compared to the expected rise during the no-policy alternative. The impact in the rural area will be much larger, which could see a reduction of around $45 \%$ in 2030. Biomass and gas will be used to compensate for the lack of coal, while demand for electricity will remain nearly unaffected, likely because it is too expensive for many to use.

\subsection{Policy 2: Coal tax}

A coal tax will have limited effect in the urban area: a large incremental increase in coal price fails to induce significant change in energy demand. This lack of response is likely because coal consumption is already low in the urban area, meaning that the overall impact it can have is minimal. Another reason is that people that are using coal are likely not doing so for monetary reasons. Making coal more expensive will therefore have limited effect, especially since it remains cheaper than gas or electricity.

In the rural area, a coal tax will have a significant impact on the overall energy demand. A substantial part of the population uses coal as people are unable to afford the cleaner alternatives. As with the coal ban policy, if coal will become less readily accessible and affordable alternatives lack, households will consume less energy. Although this reduction starts out minimal, the changes eventually add up due to the incremental tax increase. This leads to demand reductions of between $14 \%$ and $30 \%$ in 2030 compared to the no-policy alternative. As an alternative, people will revert to using 'free' biomass. As coal in China is very cheap, a monetary method to discourage consumption needs a significant price increase.

A coal tax should not be ignored as a viable policy for emission reduction as it is effective in reducing $\mathrm{PM}_{10}$ emission levels, while the effect on carbon dioxide emissions is less impactful. Even if the tax rate is high, carbon dioxide emissions will not drop further than $15 \%$ by 2030 . On the other hand, $\mathrm{PM}_{10}$ emissions could reduce up to $40 \%$ by 2030 . The policy does not necessarily cause the emissions to reduce, but instead reduces the rate at which emissions increase as a result of increased energy consumption, which will be helpful in reaching the peak carbon emission value sooner.

\subsection{Policy 3: Electricity subsidy}

Reducing the price of electricity will have a positive impact on energy demand in the rural area, while the demand in the urban area remains constant. The energy demand in the urban area will be unaffected, but the composition of fuel demand will change, causing a slight decrease in $\mathrm{PM}_{10}$, while $\mathrm{CO}_{2}$-emissions remain constant.

There is an initial decrease of around $10 \%$ in both $\mathrm{CO}_{2}$ and $\mathrm{PM}_{10}$ emissions by 2025 , yet the policy could eventually lead to higher emissions in 2030, where the $\mathrm{PM}_{10}$ and $\mathrm{CO}_{2}$ emissions can increase to $10-16 \%$ compared to the no-policy scenario. This is because the rural energy demand keeps increasing at an average yearly rate between 2025 and 2030 (964 TJ per year, as opposed to $553 \mathrm{TJ}$ in the baseline scenario). A reduction in electricity price will also reduce the price of consumption of other appliances of which the fuel is non-substitutable (such as microwaves or televisions). A price reduction will likely lead to an increase in energy consumption rather than a shift from undesirable to desirable fuels. 


\subsection{Policy 4: Additional gas pipelines}

Placing additional gas pipelines at an increased rate will be mostly effective in the urban area. Increasing the convenience is very effective and therefore such a policy will see a short-term decrease of biomass and coal consumption by about $10 \%$. In the long term, additional precautions need to be taken. Once the urban area is fully connected to the national gas grid, there is no additional convenience from this policy. This will eventually cause coal and biomass consumption to readjust to normal levels. However, this policy is the least effective policy in the rural area. On top of that, it will be practically difficult to connect the rural area to the natural gas grid.

\subsection{Policy 5: Increasing awareness}

When considering increasing the awareness of residents there is a clear decrease in emission levels. This is mostly caused by citizens moving away from coal as their primary source of fuel. The largest shift concerns one from coal towards biomass. This change causes a significant decrease in both carbon dioxide and $\mathrm{PM}_{10}$ emission levels. Household $\mathrm{CO}_{2}$-emissions can reduce by around $12-17 \%$ in 2030 , while $\mathrm{PM}_{10}-$ emissions can reduce to around $20-25 \%$ of the expected no-policy level. This means that the policy is good at achieving desired result of reducing emissions but fails to stimulate consumption of the cleaner fuels in lieu of the reduced coal demand. By 2030, biomass consumption will increase by around $25 \%$, while coal consumption can reduce by $25-35 \%$. This is because there is no change in convenience or price and while the consumption of coal is discouraged, citizens are unlikely to move to more expensive fuels as they have no incentive to do so.

This policy has higher levels of risk because there are no restrictions placed on individual citizens. This means that the government is dependent on the free will and cooperation of its citizens as a result of policy implementation. The effectiveness of such a policy is debatable especially since citizens are aware of the minimal impact, they as an individual household have on emission levels. It is uncertain whether people will change their energy consumption to the extent that they mentioned during survey and interviews. Knowing how to take action does not equal taking action. Furthermore, despite the importance for citizens to become more knowledgeable about energy consumption, the government can also not expect for the citizens to make significant changes by themselves. The people cannot be expected to make the autonomous choices that the government generally makes for them. For this reason, such a policy is unlikely to be successful on its own and should always be implemented in combination with another policy.

\subsection{Policy combinations}

Combining two policies can have a larger impact as the effects from two policies may be able to amplify the results of one another. A combined policy composed of a restrictive and supportive policy can negate the adverse effects of one as consumption can be channelled to another fuel.

Policy combinations that include a coal ban cause a direct reduction in energy demand. The reduction has lasting effects and will lead to a general reduction in energy consumption, in the urban as well as the rural area. Considering the energy demand of the urban area, there are two distinguishable groups of policy combinations: those that include a coal ban, and those that do not. The coal ban immediately reduces urban carbon dioxide emissions by around $10 \%$. An additional reduced rate of increase in energy consumption as a result of the ban, can mean a reduction of $35-40 \%$ in $\mathrm{CO}_{2}$-emissions 2030 compared to the baseline scenario.

Providing electricity subsidies leaves more room for increasing overall energy consumption. The policy combinations that include an electricity subsidy show promising results. Combining this policy with increasing exposure can reduce emissions significantly. Even though overall consumption increases due to the subsidy provided, the consumption of coal sees a decline due to the exposure. This combination shows that policies can compensate one another to have a more desirable impact. In the short term, the impact of the electricity subsidy will cause a direct decrease in emission levels, however unlike during the single policy implementation, the faster increase in consumption of the undesirable fuels is negated as citizens are encouraged to shift their fuel of consumption as a result of the improved knowledge of households.

The policy combination that includes a coal ban, combined the electricity subsidy shows a lower demand in energy than the single implementation of the coal ban policy. The ban means only three fuel options are available and forces a significant portion of the population to shift to electricity. Due to the electricity subsidy, many people decide to shift to electricity as an alternative, however, because the price of electricity is still significant, there is a lower average per household consumption of electricity. Future research needs to be done in order to validate whether this behaviour is representable of that of the population, or if further adjustments need to be made to the model to improve its validity concerning this policy combination.

\section{Conclusion}

To investigate household energy transitions in lowtier prefectures in China, this paper studied the case of Jingmen, conducted interviews and surveys, and developed simulation models to understand the household energy consumption behaviour and the impact of potential policy interventions. A system dynamics (Vensim) model, that simulates policies and 
household consumption behaviours, is linked with an energy (LEAP) model to estimate the corresponding emissions under different policy scenarios.

Five policy options and their duo combinations are investigated: coal ban, coal tax, electricity subsidy, additional gap pipelines, and more exposure to clean energies. The experiments show that although policies on coal ban or coal tax are effective in reducing emissions, they will severely impact the overall energy consumption of the residents. These policies are more effective in combination with supportive policies such as an increase in gas pipeline placement or an electricity subsidy. The policy of electricity subsidy can create transition towards electricity and reduces emissions, but it is not effective on its own as it may merely increase demand. It hence shall be implemented with a restrictive policy. In addition, exposing the population to clean energy can be effective as people become more aware of the dangers of coal consumption. However, as this policy depends on the cooperation of citizens on a large scale, its actual effectiveness is uncertain. Increasing the placement of gas pipelines has little impact in the long-term but can be effective to create a fast transition from coal to natural gas consumption. Future work shall design and investigate supportive policy options for the adoption of local renewable generations.

\section{Acknowledgement}

This study is a part of the "Study on the Synergetic Mechanism of Urban Energy Structure, Carbon Emission and Air Pollution", granted by the 2020 International Cooperation Projects of Shenzhen Science and Technology Innovation Committee, China.

\section{References}

Alem, Y., Beyene, A. D., Köhlin, G., \& Mekonnen, A. (2016). Modeling household cooking fuel choice: A panel multinomial logit approach. Energy Economics, 59, 129-137. https://doi.org/10.1016/j.eneco.2016.06.025

Bildik, Y., Daalen, C. E. Van, Yü, G., Ortt, J. R., \& Thissen, W. A. H. (2015). Modelling Wind Turbine Diffusion: A comparative study of California and Denmark 1980-1995. International Conference of the System Dynamics Society, 1-25.

CEIC. (2019). China Electricity Price - China CN: Service Price: 36 City Avg: Electricity: for Resident: 220v. Retrieved from: https://www.ceicdata.com/en/china/electricityprice [Accessed: 09/06/20]

Climate Action Tracker. (2019). Country Summary: China. Retrieved from: https://climateactiontracker.org/countries/china/ [Date Accessed: 18/10/2019]

Delang, C. O. (2016). China's Air Pollution Problems.
Routledge.

Dong, K. Y., Sun, R. J., Li, H., \& Jiang, H. D. (2017). A review of China's energy consumption structure and outlook based on a long-range energy alternatives modeling tool. Petroleum Science, 14(1), 214-227. https://doi.org/10.1007/s12182016-0136-z

Energy Information Administration (EIA). (2020). China Emission Data. Retrieved from: https://www.eia.gov/international/data/country/C HN

Gilley, B. (2012). Authoritarian environmentalism and China's response to climate change. Environmental Politics, 21(2), 287-307. https://doi.org/10.1080/09644016.2012.651904

Gu, Y., Wong, T. W., Law, C. K., Dong, G. H., Ho, K. F., Yang, Y., \& Yim, S. H. L. (2018). Impacts of sectoral emissions in China and the implications: air quality, public health, crop production, and economic costs. Environmental Research Letters, 13(8), 084008.

Hosier, R. H., \& Dowd, J. (2002). Household fuel choice in Zimbabwe. Resources and Energy, 9(4), 347361. https://doi.org/10.1016/0165-0572(87)90003$\mathrm{x}$

Huang, Y., Bor, Y. J., \& Peng, C. Y. (2011). The longterm forecast of Taiwan's energy supply and demand: LEAP model application. Energy Policy, 39(11), https://doi.org/10.1016/j.enpol.2010.10.023 $6790-6803$.

Huang, Y., \& Warnier, M. (2019). Bridging the Attitude-Behaviour Gap in Household Energy Consumption. In 2019 IEEE PES Innovative Smart Grid Technologies Europe (ISGT-Europe) (pp. 1-5). IEEE.

Hubei Provincial Bureau of Statistics. (2020). 荆门市统计年鉴 [Jingmen Statistical Yearbook Data]. Retrieved http://tjj.hubei.gov.cn/tjsj/sjkscx/tjnj/gsztj/jms/ [Date Accessed: 04/06/2020]

Hubei Province Provincial People's Government. (2018). 荆门市城镇化率大幅提升 [Jingmen City's urbanization rate has increased significantly]. Retrieved from: http://www.hubei.gov.cn/xxbs/szbs/jms/201805/t2 0180508_1284145.shtml [Date Accessed: $22 / 10 / 2019]$

$\mathrm{Hu}, \mathrm{G}$. , \& $\mathrm{Mu}, \mathrm{X}$. (2019). Analysis of urban energy metabolic system: An ecological network framework and a case study for Beijing. Journal of Cleaner Production, 210, 958-969. https://doi.org/10.1016/j.jclepro.2018.11.088

Hu, S., Yan, D., Guo, S., Cui, Y., \& Dong, B. (2017). A survey on energy consumption and energy usage behavior of households and residential building in 
urban China. Energy \& Buildings, 148(2017), 366378. https://doi.org/10.1016/j.enbuild.2017.03.064

Jia, H. (2018). China digs deep on environmental research. Retrieved from: https://www.natureindex.com/news-blog/chinadigs-deep-on-environmental-research [Date Accessed: 17/09/2019]

Jiang, L., \& O'Neill, B. C. (2004). The energy transition in rural China. International Journal of Global Energy Issues, 21(1-2), 2-26. https://doi.org/10.1504/IJGEI.2004.004691

Latif, S. A., Omar, M. S., Bidin, Y. H., \& Awang, Z. (2013). Role of Environmental Knowledge in Creating Pro-Environmental Residents. Procedia Social and Behavioral Sciences, 105, 866-874. https://doi.org/10.1016/j.sbspro.2013.11.088

LEAP. (n.d.). TED: Technology And Environmental Database., Retrieved from: http://www.energycommunity.org/WebHelpPro/T ED/TED_Intro.htm

Liao, H., Chen, T., Tang, X., \& Wu, J. (2019). Fuel choices for cooking in China: Analysis based on multinomial logit model. Journal of Cleaner Production, 225, 104-111. https://doi.org/10.1016/j.jclepro.2019.03.302

Muller, C., \& Yan, H. (2014). Household Fuel Use in Rural China. (June), 1-38. Retrieved from https://afse2016.sciencesconf.org/98089/documen $\mathrm{t}$

Molero-Simarro, R. (2017). China Economic Review Inequality in China revisited . The effect of functional distribution of income on urban top incomes, the urban-rural gap and the Gini index, 1978 - 2015. China Economic Review, 42, 101-117. https://doi.org/10.1016/j.chieco.2016.11.006

National Development and Reform Commission. (2008). Main Functions of Departments of the NDRC - Department of Climate Change. Retrieved from:

http://en.ndrc.gov.cn/mfod/200812/t20081218_25 2201.html [Accessed: 03/07/19]

Ou, J., Meng, J., Zheng, J., Mi, Z., Bian, Y., Yu, X., ... Guan, D. (2017). Demand-driven air pollutant emissions for a fast-developing region in China. Applied Energy, 204, 131-142. https://doi.org/10.1016/j.apenergy.2017.06.112

Paço, A., \& Lavrador, T. (2017). Environmental knowledge and attitudes and behaviours towards energy consumption. Journal of Environmental Management, 197, 384-392. https://doi.org/10.1016/j.jenvman.2017.03.100

Qi, Y., Ma, L., Zhang, H., \& Li, H. (2008). Translating a Global Issue Into Local Priority. The Journal of Environment \& Development, 17(4), 379-400. https://doi.org/10.1177/1070496508326123
Sahu, B. K. (2018). Wind energy developments and policies in China: A short review. Renewable and Sustainable Energy Reviews, 81(April 2017), 13931405. https://doi.org/10.1016/j.rser.2017.05.183

Sandalow, D. (2018). Guide to Chinese Climate Policy 2018. Columbia University School of International and Public Affairs, Center on Global Energy Policy, (July), 1-139.

Shin, H. C., Park, J. W., Kim, H. S., \& Shin, E. S. (2005). Environmental and economic assessment of landfill gas electricity generation in Korea using LEAP model. Energy Policy, 33(10), 1261-1270. https://doi.org/10.1016/j.enpol.2003.12.002

Stockholm Environment Institute (SEI). (2005). LEAP: Long Range Energy Alternatives Planning System, User Guide for LEAP 2005. Retrieved from: http://forums.seib.org/leap/documents/Leap2005 UserGuideEnglish.pdf,2005S.

Struben, J., \& Sterman, J. D. (2008). Transition challenges for alternative fuel vehicle and transportation systems. Environment and Planning B: Planning and Design, 35(6), 1070-1097. https://doi.org/10.1068/b33022t

Su, M., Chen, C., \& Yang, Z. (2016). Urban energy structure optimization at the sector scale: Considering environmental impact based on life cycle assessment. Journal of Cleaner Production, 112 , $1464-1474$ https://doi.org/10.1016/j.jclepro.2015.01.059

The People's Government of Jingmen Municipality. (2019). About Jingmen. Retrieved from: http://www.jingmen.gov.cn/col/col4232/index.htm 1 [Date Accessed: 22/10/2019]

Wang, H., Lu, X., Deng, Y., Sun, Y., Nielsen, C. P., Liu, Y., ... \& McElroy, M. B. (2019). China's CO2 peak before 2030 implied from characteristics and growth of cities. Nature Sustainability, 2(8), 748754.

Wang, K., Wang, Y. X., Li, K., \& Wei, Y. M. (2015). Energy poverty in China: An index based comprehensive evaluation. Renewable and Sustainable Energy Reviews, 47, 308-323. https://doi.org/10.1016/j.rser.2015.03.041

Wang, T. J., Jin, L. S., Li, Z. K., \& Lam, K. S. (2000). A modeling study on acid rain and recommended emission control strategies in China. 34.

Yang, X. J., Hu, H., Tan, T., \& Li, J. (2016). China's renewable energy goals by 2050. Environmental Development, 20(October), 83-90. https://doi.org/10.1016/j.envdev.2016.10.001

Yue, T., Long, R., Liu, J., Liu, H., \& Chen, H. (2019). Empirical Study on Households, EnergyConservation Behavior of Jiangsu Province in China: The Role of Policies and Behavior Results. https://doi.org/10.3390/ijerph16060939 
Zhao, S., \& Alexandro, A. (2019). Current and future struggles to eliminate coal. 129(February), 511520. https://doi.org/10.1016/j.enpol.2019.02.031 